\title{
Pedagogy in a Pandemic - Leave No Trainee Behind
}

\author{
Abhiram Kanneganti ${ }^{1}$, Karen Lim $^{1}$, Grace Chan ${ }^{1}$, Soe-Na Choo ${ }^{1}$, Mahesh Choolani ${ }^{2}$, Ida \\ Ismail-Pratt ${ }^{1}$, and Susan Logan ${ }^{1}$ \\ ${ }^{1}$ National University Hospital \\ ${ }^{2}$ National University Singapore Yong Loo Lin School of Medicine
}

April 28, 2020

First gaining worldwide attention in February 2020, COVID-19 has infected 500,000, and taken the lives of 21,000 as of the $27^{\text {th }}$ March $2020^{1}$. In response to the rapidly escalating global crisis, most countries have employed drastic measures such as travel bans and nationwide lockdowns in an urgent attempt to slow down viral spread so as not to overwhelm limited healthcare resources. "Social distancing" is the catchphrase of the day. Singapore saw her first imported case on the $23^{\text {rd }}$ January $2020^{2}$ and felt déjà vu, having experienced the Severe Acute Respiratory Syndrome [SARS] outbreak in 2003.

Singapore's response to SARS demonstrated two key priorities: sustainability of patient care and protection of healthcare professionals [HCPs]. While manpower was reorganised into teams segregated by time, place and expertise, many important hospital functions such as medical education and intermediate exam preparation for specialist trainees $[\mathrm{STs}]$ were ignored ${ }^{3}{ }^{4}$. The only training was "on-the-job," focusing on essential care. Both specialist and general training for junior doctors was neglected despite their frontline role. The situation with COVID-19 is no different, and globally we are already witnessing a negative impact on education and training 5 . While understandable, work-arounds do exist. In Singapore, we have been preparing for this ${ }^{6}$ and our unit made it an early priority to continue medical education while balancing increased service needs and the requirement to avoid congregation. With the COVID-19 pandemic expected to last until the end of 2020 and possibly beyond, we share our strategies.

To safeguard HCPs and ensure continuity of services in the inevitable event that HCPs contract COVID-19, hospitals nationwide have implemented team segregation. In our department, different teams work shifts to cover five geographically distinct service areas- outpatient services [two teams], emergency department [four teams], labour ward [four teams], sonography unit [two teams] and inpatient services [two teams]. The greatly increased manpower needs, non-standard working hours, the need to avoid congregation and depletion of staff through illness initially stopped our morning didactic sessions. However, within two weeks, we started using videoconferencing methods for synchronous distance teaching. While the use of videoconferencing in medical education is not new ${ }^{78}$, it has found revived utility in these times. The lead and assistant program directors created a timetable with topics blueprinted to the Royal College of Obstetricians and Gynaecologists membership examination [MRCOG] syllabus incorporating Green Top Guidelines, NICE guidelines, TOG articles and other RCOG documents such as consent advice, good practice, scientific impact papers, audits and key publications. This timetable was divided amongst the STs who committed to 1-2 sessions each per month. They were encouraged to select topics which represented personal knowledge gaps. The format comprises a 30-minute presentation with assessment of learning through Q\&A, EMQs or SBA. These sessions are facilitated by senior faculty with our programme coordinators tracking education hours and attendance by verifying on-screen presence. We hold sessions at $0730 \mathrm{hrs}$ as it constitutes a quieter period prior to hand over and when most STs are awake. Those who are commuting, off work, or on quarantine / stay home notice still find it easy to participate.

Zoom ${ }^{\circledR}$ [Zoom Video Communications Inc., San Jose, California, USA] has several features which have 
greatly assisted our mission. The most significant is its stability over a wide variety of platforms [i.e. smart phones and computers] running different operating systems over local $4 \mathrm{G}$ networks. Presenters found the "Share Screen" function very user friendly to allow voice-over teaching with their presentation slides. A pre-determined, recurrent meeting code is fixed for the morning session. Zoom ${ }^{\circledR}$ also allows recordings of the session which are stored on a hospital-based intranet server together with the presentation slides and the source guideline or article. This serves as a form of asynchronous teaching for those who missed the session or wish to revise.

Comical usage of virtual backgrounds and participation of some our STs' very young children at home brought in humour and gave a sense of solidarity at a time of isolation. Senior STs revealed themselves as natural peer trainers regarding exam technique. Interestingly, some of our junior STs felt that this style of teaching was more interactive than our typical Departmental didactic sessions. One remarked, "Zoom ${ }^{\circledR}$ meetings are more fun and meaningful because they are directed at what is really important for us to know and it is easy to ask questions fearlessly." This is a positive consequence as many cultures fear "losing face" by asking questions in an audience of senior faculty. The end of the meeting also allows for any "on the ground" operational issues to be raised while serving as a conduit to pass on information from department leaders.

A vital aspect of Singapore's response to COVID-19 was to cut all non-time-sensitive surgical cases in order to boost surge critical care capacity and redistribute manpower and resources. In our unit, there is an 80$90 \%$ reduction in operating for benign gynaecology cases with only obstetric and gynaecologic oncology cases proceeding. Due to manpower constraints, all surgeries and on-table consultations are being undertaken by consultants with house officer assistance. As a result, STs' gynaecological operative training has been greatly reduced. To partly address this, we started Zoom ${ }^{\circledR}$-based surgical sharing sessions by experienced faculty, taping segments of current surgical cases or using archived videos to train on anatomy, surgical principles and pre- and post-operative care. A session on the management of ovarian cysts in pregnancy coincided with three recent cases and was particularly well received. Although videoconferencing has a role in surgical training ${ }^{9}$, it is very clear that it will not entirely remedy case-log deficiencies and the loss of hands-on experience. Simulators housed within the Department are available for individual use and we plan to incorporate these into "live" sessions.

The MRCOG examinations, which are used to certify competence for progression within Singapore's obstetrics and gynaecology specialist training programme, have been postponed ${ }^{10}$. To keep our exam candidates' preparedness honed while waiting for the next exam window, we have also continued in-house Zoom ${ }^{\circledR}$ OSCE practice sessions. Prior to this pandemic, our STs were supported to take up RCOG Associate status in order to facilitate access to the RCOG's excellent e-learning ${ }^{11} 12$ portal. We strongly recommend it as a staple for asynchronous learning as it is a repository for a wide array of modules pertaining to core knowledge, case discussions, technical skills and professionalism. Many Colleges globally have similar material, and these should be explored.

This pandemic will undoubtedly affect the training and psychosocial wellbeing of STs who constitute a major component of the frontline staff. Disruption to training affects confidence and exam cancellations instil fear for the future as key purchases and family plans are put on hold. However, while this pandemic is expected to last until the end of the year, women's health issues will continue to exist. It is important for the global community of obstetricians and gynaecologists to start seeing how to ensure continuity of training in this new environment. We offer a few simple suggestions on how to achieve this despite dyssynchronous rosters, home stay notices, anxiety, exhaustion and illness. Anecdotally, our STs report have found solidarity in a time of isolation through these morning sessions and it probably contributes to their ability to cope. The pandemic of today is daunting. We need to support our STs because to do so is to invest into the future of women's health.

\section{Word Count: 1214}

\section{Disclosure of Interests:}


The authors of this manuscript have no relevant financial, personal, political, intellectual or religious interests to declare

\section{Contribution to authorship:}

AK, KMXL, GMFC, SNC and SJSL had an equal role in conceiving and writing this commentary

MAC and IIP critically reviewed this manuscript

Details of ethics approval: Not applicable

Funding: Not applicable

\section{Acknowledgements:}

The authors acknowledge the roles of Xiu Cai Wong Edwin and Lee Boon Kai in the running of our distance learning programme

\section{References}

1. Organisation WH. Coronavirus Disease (COVID-19) Situation Dashboard 2020 [Available from: https://experience.arcgis.com/experience/685d0ace521648f8a5beeeee1b9125cd accessed 28th Mar 20.

2. Public Communications Division MoCaI, Government of Singapore. Coronavirus disease 2019: Cases in Singapore; A timeline of the confirmed cases in Singapore. 2020

3. Sherbino J, Atzema C. "SARS-Ed": severe acute respiratory syndrome and the impact on medical education. Ann Emerg Med2004;44(3):229-31. doi: 10.1016/j.annemergmed.2004.05.021 [published Online First: 2004/08/28]

4. Rambaldini G, Wilson K, Rath D, et al. The impact of severe acute respiratory syndrome on medical house staff: a qualitative study.J Gen Intern Med 2005;20(5):381-5. doi: 10.1111/j.1525-1497.2005.0099.x [published Online First: 2005/06/21]

5. Hui DSC, Zumla A. Severe Acute Respiratory Syndrome: Historical, Epidemiologic, and Clinical Features. Infect Dis Clin North Am2019;33(4):869-89. doi: 10.1016/j.idc.2019.07.001

6. Lim EC, Oh VM, Koh DR, et al. The challenges of "continuing medical education" in a pandemic era. Ann Acad Med Singapore2009;38(8):724-6. [published Online First: 2009/09/09]

7. Markova T, Roth LM, Monsur J. Synchronous distance learning as an effective and feasible method for delivering residency didactics.Fam Med 2005;37(8):570-5. [published Online First: 2005/09/08]

8. Valaitis R, Akhtar-Danesh N, Eva K, et al. Pragmatists, positive communicators, and shy enthusiasts: three viewpoints on Web conferencing in health sciences education. J Med Internet Res 2007;9(5):e39. doi: 10.2196/jmir.9.5.e39 [published Online First: 2008/01/02]

9. Augestad KM, Lindsetmo RO. Overcoming distance: video-conferencing as a clinical and educational tool among surgeons. World J Surg2009;33(7):1356-65. doi: 10.1007/s00268-009-0036-0 [published Online First: $2009 / 04 / 23]$

10. RCOG. Coronavirus (COVID-19) MRCOG Part 3 communications: MRCOG Part 3 exam postponement 2020 [Available from: https://www.rcog.org.uk/en/careers-training/mrcog-exams/part-3-mrcog-exam/covid$19 /$.

11. Saunders H, Hundal K, Mires GJ. StratOG.net: the RCOG's online learning resource to support curriculum delivery and postgraduate training. The Obstetrician \& Gynaecologist 2010;12(3):193-98. doi: 10.1576/toag.12.3.193.27602

12. RCOG. RCOG eLearning 2007 [cited 2020. Available from: https://elearning.rcog.org.uk/. 